\title{
A Journal Article Critique of "Motivational Interviewing and Exercise Program for Community-Dwelling Older Persons with Chronic Pain"
}

\author{
Hamzah M. Alghzawi ${ }^{*}$, Fatima K. Ghanem² \\ ${ }^{1}$ Medstar Good Samaritan Hospital, Maryland, USA \\ ${ }^{2}$ Al Albayt University, Mafraq, Jordan \\ Email: `hamzahjordan87@umaryland.edu; ‘hamzahjordan87@gmail.com
}

How to cite this paper: Alghzawi, H.M. and Ghanem, F.K. (2021) A Journal Article Critique of "Motivational Interviewing and Exercise Program for Community-Dwelling Older Persons with Chronic Pain". Open Access Library Journal, 8: e7456.

https://doi.org/10.4236/oalib.1107456

Received: April 26, 2021

Accepted: May 28, 2021

Published: May 31, 2021

Copyright () 2021 by author(s) and Open Access Library Inc.

This work is licensed under the Creative Commons Attribution International License (CC BY 4.0).

http://creativecommons.org/licenses/by/4.0/

\begin{abstract}
This article provides a critical review of a published article entitled "Motivational Interviewing and Exercise Program for Community-Dwelling Older Persons with Chronic Pain". The reviewed article aimed to examine the effectiveness of an integrated motivational interviewing and physical exercise program (MIE) on pain, physical and psychological functions, quality of life, self-efficacy, and compliance with exercise. A randomized pretest-posttest with a control group experimental design was used in this study to attain its objectives. The researcher followed the conceptual framework of total pain to define chronic pain. Despite some threats that existed in the study design that might affect its empirical power and reputation, the study was worthwhile in testing Motivational Interviewing and Exercise Program. Health care providers need to consider its shortfalls while using the study findings and researchers should consider these threats when conducting future research.
\end{abstract}

\section{Subject Areas \\ Geriatrics, Kinesiology}

Keywords

Article Review, Flaws, Critique, Motivational Interview, Chronic Pain

\section{Introduction}

A critical reading and analysis was conducted on an Article published by Tse et al. [1] in the Journal of Clinical Nursing entitled: Motivational Interviewing and 
Exercise Program for Community-Dwelling Older Persons with Chronic Pain, available online at: https://pubmed.ncbi.nlm.nih.gov/23279630/.

\section{Background}

\subsection{Purpose and Hypothesis}

The purpose of this study was to examine the effectiveness of an integrated motivational interviewing and physical exercise program (MIE) on pain, physical and psychological functions, quality of life, self-efficacy, and compliance with exercise. The aim was clearly and consistently stated in both the abstract and the background. However, it would be completely consistent if the authors did not remove the quality of life concept from the aim statement in the background; since quality of life was one of the measured outcomes the authors aimed to examine.

The authors followed the aim statement with a clearly stated hypothesis that "integrated MIE would reduce the severity of pain, improve physical and psychological well-being, improve quality of life, increase self-efficacy and have a high compliance rate for community-dwelling older persons with chronic pain" (p.1845). This directional hypothesis was consistent with aim statement.

\subsection{Quality of Existing Evidence}

It is clear that the authors built their hypothesis based on the findings from three randomized controlled trials conducted by Friedrich et al. [2] [3] and by Vong et al. [4]. According to JHNEBP evidence rating scales [5], these studies are at the highest level of scale (level I), which means that these studies are high quality studies. The readers may think that the authors should have displayed more studies to support their hypothesis; however, searching the literature on this topic did not provide other studies.

\subsection{Knowledge Gap and Study's Contributions}

In the background section, the authors introduced the readers to the definition of main concepts in the study, such as; chronic pain, motivational interviewing, and the physical exercise as intervention to reduce the pain. Additionally, they displayed the studies that supported the effectiveness of the MIE program on physical and psychological well-being among people with chronic low back pain. According the authors, the gap in the knowledge is "a lack in studies investigating the effectiveness of this integration on older adults with chronic pain" (p. 1845). This is the first study that examined the effectiveness of MIE program on elderly people with chronic low back pain. This study sounds interesting and would contribute to health knowledge.

\subsection{Conceptual Framework}

The authors used the conceptual framework of total pain that suggested by 
Saunders to define chronic pain. Total pain is a multi-faceted set of physical symptoms, mental distress, social and emotional problems [6]. The authors used this conceptual framework as a general framework for pain management. Moreover, the authors used this conceptual framework in determining the outcomes that should be measured and in interpreting the study results.

\section{Methodology}

\subsection{Study Design and Data Collection}

A randomized pretest-posttest with control group experimental design was used in this study. The main advantage of this design is that it increases the likelihood that the change in the outcome is only related to the intervention and thus decreases the chances of confounding due to other factors [7]. The design was also a blind trial; in other words, the participants were not told about the group allocation. This type of clinical trial improves the construct validity. The author described the design and the sample together in the same section. However, it would be more organized if the design and sample are described separately. According to the authors, the data was collected from the intervention and control groups at two times; the first time was before the program (baseline assessment), and the second time was a posttest assessment ( 8 weeks later). Table 1 describes Campbell and Stanley notation for this design [7].

Table 1. Campbell \& Stanley notation for the study design.

\begin{tabular}{|c|c|c|c|}
\hline \multicolumn{2}{|c|}{ Baseline ( $1^{\text {st }}$ week) } & \multicolumn{2}{|r|}{ Posttest ( $8^{\text {th }}$ week) } \\
\hline $\mathrm{R}$ & $\mathrm{O}$ & $\mathrm{X}$ & $\mathrm{O}$ \\
\hline $\mathrm{R}$ & $\mathrm{O}$ & & $\mathrm{O}$ \\
\hline
\end{tabular}

\subsection{Research Sample}

The sampling design for this study appears not to have been well planned. The authors did not mention if they determined the sample size of participants based on the calculation of power analysis and t effect size. Based on the Thorndike's rule (at least 10 - 20 per variable), the sample size seems low [8]. The 56 participants were recruited by convenience sampling from two community centers for the elderly, and the randomization was just in the assigning the two centers into experimental and control groups. The inclusion criteria were clearly stated, and they included "people aged 65 and above, suffering from chronic musculoskeletal pain for more than three months [meeting the definition of the International Association for the Study of Pain]" (p. 1846) [9]. A good feature of the article is the use flowchart to help the readers in understanding the recruitment process. Convenience sampling is one of the non-probability sampling methods, and it is the weakest one. It increases the sampling bias and makes the sample less representative of the entire population. Moreover, it limits the chance of generalization to the entire population. 


\subsection{Measurement Reliability and Validity}

The authors provided a clear description for all instruments used in the study. The authors assessed the reliability and the validity of each one, and they stated that all instruments are reliable, valid, and appropriate for measuring the outcomes. They supported their judgment based on the values of Cronbach's alpha, test-retest reliability, and internal consistency for these instruments. The Cronbach's alpha for all instruments is greater than 69 , and this confirms their reliability. Table 2 summarizes the Cronbach's alpha for all instruments.

Table 2. Summary of the instruments and their Cronbach's alpha.

\begin{tabular}{cc}
\hline Instruments & Cronbach alpha \\
\hline Numerical Rating Scale (NRS) & 0.89 \\
Elderly Mobility Scale (EMS) & 0.88 \\
Pain Self-Efficacy Questionnaire (PSEQ) & 0.95 \\
State-Trait Anxiety Inventory (STAI) & 0.90 \\
Subjective Happiness Scale (SHS) & 0.69 \\
Geriatric Depression Scale-Short Form (GDS) & 0.90 \\
Health Survey Short Form 12 & 0.76 \\
\hline
\end{tabular}

\subsection{Human Subjects Issues}

The researchers considered human subjects' issues in their study design. According to the authors, the study was approved by the human subjects' ethics committee of a local university, and written informed consent was obtained from each participant before the study (p. 1846). Moreover, the authors stated that they would invite the control group to the MIE program at the end of the study, and this maintains the right of justice between intervention and control group.

\subsection{Threats to Design Validity}

The study has many threats to validity. However, the authors tried to control some of them. The sample size was not calculated based on the power analysis and the effect size, and based on the Thorndike's rule (at least 10 - 20 per variable) [8], the sample size $(\mathrm{N}=56)$ seems small. The small sample size threatens statistical conclusion validity by producing low statistical power. Another threat to statistical conclusion validity was using many instruments to measure many outcomes. Using many instruments in the same study threatens statistical conclusion validity by producing fishing and error rate problems. Moreover, using many instruments threatens internal validity by producing testing threat because testing an outcome by specific instrument may affect the measurement of other outcome by other instrument.

Another threat to internal validity was attrition as three participants were lost because of difficulty in follow up, and it seems that the author did not take any action to avoid this threat as evidenced by choosing small sample size. Participants 
were recruited by convenience sampling method, which made the sample less representative and thus threatened the external validity and reduced the chance of generalizability. It seems that the authors tried to improve internal validity and remove other explanations for the outcome rather than the intervention by dividing two elderly community centers with similar location and demographic status into control group and intervention group. The authors used blind trial in this study so that the participants did not know if they were in the control or intervention group, and it seems that the authors did blind trial to maintain construct validity by removing threats such as resentful demoralization, compensatory rivalry, and reactivity to experimental situation.

\section{Results}

\subsection{Data Analysis}

The authors clearly stated the results of their study. They used tables to display the results of data analysis, and these tables include all details (including all significant and non-significant results); therefore, it was easy for the readers to understand the results from tables [10] [11] [12] [13].

The authors used appropriate statistical tests to examine intergroup and intragroup differences; however, test like Multivariate ANOVA (MANOVA) are highly recommended to more statistical control. In the narrative section of results, the authors clearly stated the most important finding, and it was consistent with tables.

\subsection{Confidence in Results and Limitations in Study Design}

The readers may have low confidence in the significant results reported in the article because of many limitations in study design and in the process of conducting the program. Regarding the study design, as is mentioned above, there were many threats on the four types of validity, and the authors should have avoided these threats to make the readers more confident in their study [14] [15] [16] [17]. In addition, there are limitations in the process of conducting the program, for example, the authors stated that they referred to "the suggestion of the World Health Organization, which suggests that people aged over 65 perform at least 150 minutes of moderate exercise per week to achieve optimal health" (p. 1849). However, the participant did a session per week for just 30 minutes; the remaining time (120 minutes) was as home exercise, and the authors was following the home exercise by phone call. Actually, I am wondering if the following up by phone guaranteed if the participants virtually did the exercise.

Furthermore, the authors justified non-significant change in the quality of life because of the short period of the program. Actually, literature confirms the effectiveness of exercise on improvement in quality of life, but only if it is sufficient (at least 150 minute per week). This could increase the reader's suspicions that the participants did not adhere to the home exercise.

The authors stated that those in the control group followed their regular activ- 
ities in the centers; however the authors did not describe these activities. In addition, the authors justified the improvement of happiness in the control group because they knew that they would also receive the program after the post treatment assessment finished. Again, the authors failed to offer important information, in other words, how the participants in control group knew to which group they had been assigned. Someone may say this was included in the consent form, but this means that the improvement of happiness among intervention group related to the same reason and not the MIE program. Overall, because of all of these limitations in study design and conducting the study; it is difficult to be confident in this study.

\section{Conclusions}

\subsection{Consistency of Conclusion and Implications}

The conclusion section was consistent with the study purpose and findings. However, the authors did not say anything about the results of quality of life in the conclusion section despite it was one of the examined outcomes. The good point in the conclusion section is that the authors recommended the application of the MIE program in caring for older people who have chronic pain.

\subsection{Level of Evidence}

The quality of this study is not high and this resulted from aforementioned threats to the internal, construct, statistical conclusion, and external validity, and also from the aforementioned limitations in conducting the program. Overall, the validity of the study is low and the authors should have controlled all of these threats to improve the quality of their study.

\subsection{Suggestions to Improve Study Design}

The authors did not discuss the validity threats in their study, and they did not provide any suggestions to avoid these threats. Actually, there are many suggestions that the authors should follow to improve their study. First, the sample size should be more than 56 participants, and it should be calculated based on the power analysis and the effect size. Increasing sample size could be achieved by recruiting participants from other centers. Adequate sample size could remove many threats in the study, such as attrition threat, low statistical power as a threat to statistical conclusion validity. The authors could recruit two more centers from similar locations but different from the locations of the first two centers, and then again dividing them into control and intervention groups. This technique would increase sample size and improve external validity and thus increase the chance of generalizability. Other threats could be controlled statistically, for example, by conducting Multivariate ANOVA (MANOVA) [18].

Furthermore, the participants should perform the exercise under direct supervision from the therapists instead of doing most of the exercises at home. They could perform the exercise in the health center over four sessions (40 minutes 
per day). This would guarantee that the program was applied correctly. Additionally, the authors should provide a full description of the regular activities provided to the control group. This would make the comparison between groups more precise.

\section{Conflicts of Interest}

The authors declare that the research was conducted in the absence of any commercial or financial relationships that could be construed as a potential conflict of interest.

\section{References}

[1] Tse, M.M., Vong, S.K. and Tang, S.K. (2013) Motivational Interviewing and Exercise Programme for Community-Dwelling Older Persons with Chronic Pain: A Randomised Controlled Study. Journal of Clinical Nursing, 22, 1843-1856. https://doi.org/10.1111/j.1365-2702.2012.04317.x

[2] Friedrich, M., Gittler, G., Halberstadt, Y., Cermak, T. and Heiller, I. (1998) Combined Exercise and Motivation Program: Effect on the Compliance and Level of Disability of Patients with Chronic Low Back Pain: A Randomized Controlled Trial. Archives of Physical Medicine and Rehabilitation, 79, 475-487. https://doi.org/10.1016/S0003-9993(98)90059-4

[3] Friedrich, M., Gittler, G., Arendasy, M. and Friedrich, K. (2005) Long-Term Effect of a Combined Exercise and Motivational Program on the Level of Disability of Patients with Chronic Low Back Pain. Spine, 30, 995-1000.

https://doi.org/10.1097/01.brs.0000160844.71551.af

[4] Vong, S.K., Cheing, G.L., Chan, F., So, E.M. and Chan, C.C. (2011) Motivationalenhancement Therapy in Addition to Physical Therapy Improves Motivational Factorstreatment Outcomes in People with Low Back Pain: A Randomized Controlled Trial. Archives of Physical Medicine \& Rehabilitation, 92, 176-183. https://doi.org/10.1016/j.apmr.2010.10.016

[5] Newhouse, R., Dearholt, S., Poe, S., Pugh, L.C. and White, K. (2005) The Johns Hopkins Nursing Evidence-Based Practice Rating Scale. The Johns Hopkins Hospital, Johns Hopkins University School of Nursing, Baltimore, MD.

[6] Clark, D. (1999) 'Total Pain', Disciplinary Power and the Body in the Work of Cicely Saunders, 1958-1967. Social Science \& Medicine, 49, 727-736. https://doi.org/10.1016/S0277-9536(99)00098-2

[7] Campbell, D.T. and Stanley, J.C. (1963) Experimental and Quasi-Experimental Designs for Research on Teaching. In: Gage, N.L., Ed., Handbook of research on teaching, Rand McNally, Chicago, IL, 171-246.

[8] Thorndike, R.L. (1996) Measurement and Evaluation in Psychology and Education. 6th Edition, Prentice Hall, Columbus, $\mathrm{OH}$.

[9] Lindblom, U., Merskey, H., Mumford, J.M., Nathan, P.W., Noordenbos, W. and Sunderland, S. (1986) Classification of Chronic Pain: Description of Chronic Pain Syndromes and Definitions of Pain Terms. Pain, 3, 216-221.

[10] Alghzawi, H. (2016) Arguments for Using Animals in Research Projects: An Ethical Consideration. Journal of Global Research in Education and Social Science, 8, 205210. https://ikprress.org/index.php/JOGRESS/article/view/2639

[11] Alghzawi, H. (2016) Cultural Impact on Mental Health Care in Saudi Arabia. Jour- 
nal of International Research in Medical and Pharmaceutical Sciences, 10, 127-132. https://www.ikprress.org/index.php/JIRMEPS/article/view/3212

[12] Alghzawi, H. (2016) The Impact of Domestic Violence on Pregnant Women: A Review Article. Journal of Disease and Global Health, 8, 153-162. https://www.ikprress.org/index.php/JODAGH/article/view/2714

[13] Alghzawi, H. (2018) Probability and Correlates of Nicotine Dependence among Smokers with and without Major Depressive Disorder: Results from the National Epidemiology Survey on Alcohol and Related Conditions. Perspectives in Psychiatric Care, 54, 354-364. https://doi.org/10.1111/ppc.12255

[14] Alghzawi, H., ALBashtawy, M., Azzeghaiby, S. and Alzoghaibi, I. (2014) The Impact of Wars and Conflicts on Mental Health of Arab Population. International Journal of Humanities and Social Science, 4, 237-242.

[15] Alghzawi, H.M., Hourani, R.A., Alrashaida, B.M., Hamdan-Mansour, A. and Bayomi, M. (2014) Discharge Policy Analysis in Prince Hamzah Hospital. Health, 6, 3022-3029. https://doi.org/10.4236/health.2014.621340

[16] Alghzawi, H.M. (2012) Psychiatric Discharge Process. ISRN psychiatry, 2012, Article ID: 638943. https://doi.org/10.5402/2012/638943

[17] Al-ghzawi, H., ALBashtawy, M., Azzeghaiby, S. and Azzeghaiby, I. (2014) Alcohol Use among Adolescents. International Journal of Humanities and Social Science, 4 , 167-175.

[18] Field, A. (2013) Discovering Statistics Using IBM SPSS Statistics. 4th Edition, Sage Thousand Oaks, CA, 11-13 and 706-716. www.sagepub.co.uk/field4e 